\title{
OriginaL
}

\section{Early liraglutide treatment improves $\beta$-cell function in patients with type 2 diabetes: a retrospective cohort study}

\author{
Yoshinobu Kondo ${ }^{1), 2)}$, Shinobu Satoh ${ }^{2)}$, Uru Nezu Osada ${ }^{3)}$ and Yasuo Terauchi ${ }^{1)}$ \\ 1) Department of Endocrinology and Metabolism, Graduate School of Medicine, Yokohama City University, Yokohama 236-0004, Japan \\ 2) Department of Endocrinology and Metabolism, Chigasaki Municipal Hospital, Chigasaki 253-0042, Japan \\ 3) Department of Endocrinology and Diabetes, Saiseikai Yokohama City South Hospital, Yokohama 234-0054, Japan
}

\begin{abstract}
Preclinical studies on liraglutide have suggested related improvements in $\beta$-cell function. Therefore, we investigated these effects in patients with type 2 diabetes (T2D) using the glucagon stimulation test (GST). We conducted a retrospective cohort study of 73 insulin-treated patients with T2D who had their treatment switched to liraglutide monotherapy. Their $\beta$-cell function was measured using a 1-mg intravenous GST at baseline and 24 weeks after treatment. The effect of liraglutide treatment on $\beta$-cell function was assessed by the change in the area under the curve (AUC) of serum C-peptide immunoreactivity during the GST (AUC-CPR). The AUC-CPR increased after 24 weeks of liraglutide treatment $(9.80 \pm 0.55 \mathrm{ng} / \mathrm{mL} \cdot \min$ to $11.50 \pm 0.52 \mathrm{ng} / \mathrm{mL} \cdot \min , p=0.001)$. In the univariate and adjusted multivariate regression analyses, a negative relationship between the change in the AUC-CPR and T2D duration was noted $(\beta=-0.22$, $95 \%$ confidence interval $[\mathrm{CI}]=-0.35$ to $-0.09, \mathrm{R}^{2}=0.14, p=0.001$ and $\beta=-0.20,95 \% \mathrm{CI}=-0.34$ to $-0.05, \mathrm{R}^{2}=0.23, p=$ 0.008 , respectively). In the analysis using T2D duration tertiles, early liraglutide treatment (T2D duration $\leq 10$ years) significantly improved the AUC-CPR $(<4$ years: $+2.56 \pm 0.73 \mathrm{ng} / \mathrm{mL} \cdot \mathrm{min}, p=0.002 ; 4-10$ years: $+2.60 \pm 0.56 \mathrm{ng} / \mathrm{mL} \cdot \mathrm{min}$, $p<0.001)$, whereas late liraglutide treatment $\operatorname{did} \operatorname{not}(>10$ years: $-0.33 \pm 1.15 \mathrm{ng} / \mathrm{mL} \cdot \mathrm{min}, p=0.78)$. We conclude that early liraglutide treatment potentially improves $\beta$-cell function and subsequently glycemic control in patients with T2D, preventing further diabetic complications.
\end{abstract}

Key words: Liraglutide, $\beta$-cell function, Diabetes duration, Type 2 diabetes, Early treatment

PATIENTS with type 2 diabetes (T2D) have a $50 \%$ lower $\beta$-cell function at diagnosis than healthy individuals, and their $\beta$-cell function continues to decline by approximately $4 \%$ annually [1]. Loss of $\beta$-cell function results in poor glucose control in these patients and accelerates the progression of diabetic complications $[2,3]$. Reduced $\beta$-cell function in patients with T2D has been reported to be attributable to accelerated apoptosis $[4,5]$.

Glucagon-like peptide 1 (GLP-1) receptor agonists are increasingly being used to treat patients with $\mathrm{T} 2 \mathrm{D}$, not only for their glucose-lowering effects but also for the associated low risk of hypoglycemia and body weight gain [6]. The demonstrated glucose-lowering effects of the GLP-1 receptor agonist liraglutide are

Submitted Apr. 9, 2015; Accepted Jul. 28, 2015 as EJ15-0206 Released online in J-STAGE as advance publication Aug. 6, 2015 Correspondence to: Yasuo Terauchi, M.D., Ph.D., Department of Endocrinology and Metabolism, Graduate School of Medicine, Yokohama City University, 3-9 Fukuura, Kanazawa-ku, Yokohama 236-0004, Japan. E-mail: terauchi@yokohama-cu.ac.jp

(C) The Japan Endocrine Society related to the preservation of adequate $\beta$-cell function in patients with T2D [7-10]. Preclinical studies with liraglutide have suggested protective effects on $\beta$ cells, including reduced apoptosis and enhanced $\beta$-cell proliferation in both rodent models and humans [11-17]. However, only few studies have assessed the effects of liraglutide on human $\beta$-cell function independent of glucose stimuli $[18,19]$. Assessment of residual $\beta$-cell function by intravenous glucagon stimulation is widely used because of its methodological simplicity and high reproducibility [20-22].

After cases of death due to diabetic ketoacidosis after switching from insulin to liraglutide therapy were reported, the Japan Diabetes Society and the GLP-1 receptor agonists' manufacturers warned that $\beta$-cell function should be assessed before liraglutide introduction [10]. In the present study, we analyzed data of patients whose $\beta$-cell function was assessed using a glucagon stimulation test (GST). The advantage of the GST over oral glucose or meal stimulation [23] is that it stimulates $\beta$ cells independent of endogenous GLP-1 levels. 


\section{Materials and Methods}

This retrospective cohort study analyzed data from the medical records of patients with T2D whose treatment was changed from insulin therapy to liraglutide monotherapy at the Chigasaki Municipal Hospital between June 2010 and August 2014. We included patients (a) with an evaluation of $\beta$-cell function using a 1-mg intravenous GST before the change to liraglutide monotherapy, (b) who continued liraglutide for 24 weeks, and (c) whose $\beta$-cell function was re-assessed by the GST 24 weeks after the start of liraglutide treatment. We excluded those with (a) fasting plasma glucose levels $\geq 180 \mathrm{mg} / \mathrm{dL}$ or $<70 \mathrm{mg} / \mathrm{dL}$ at the baseline GST (to eliminate the effect of glucotoxicity or hypoglycemia on the assessment of $\beta$-cell function), (b) positive anti-glutamic acid decarboxylase antibodies, (c) an estimated glomerular filtration rate (eGFR) $<30 \mathrm{~mL} /$ $\min / 1.73 \mathrm{~m}^{2}$, (d) liver cirrhosis, (e) steroid use, or (f) malignant comorbidity.

Liraglutide treatment was started at a dose of 0.3 $\mathrm{mg} /$ day and titrated up to $0.9 \mathrm{mg} /$ day (the maximum allowable dosage in Japan) in increments of $0.3 \mathrm{mg}$ per week. When patients were switched from insulin therapy to liraglutide monotherapy in our hospital, their $\beta$-cell function was routinely checked before and after liraglutide introduction to ensure the patients' safety and to monitor the indications for liraglutide therapy. Therefore, this study is a retrospective analysis of routinely accumulated GST data.

During the GST, $1 \mathrm{mg}$ of glucagon (Glucagon $\mathrm{G}$ Novo, Novo Nordisk, Denmark) was injected intravenously after a 10-hour overnight fast. The levels of fasting plasma glucose (FPG), plasma glucose 6 min after glucagon stimulation (Glu6), fasting serum C-peptide (CPR0), and serum C-peptide 6 min after glucagon stimulation (CPR6) were measured. Serum C-peptide (CPR) levels were measured using a chemiluminescence immunoassay kit (Siemens Healthcare Diagnostics, Eschborn, Germany). The areas under the curve (AUCs) for the CPR and FPG levels were calculated using the trapezoidal rule.

The primary endpoint was the change in the AUC of CPR levels during the GST (AUC-CPR $=$ [sum of C-peptide levels before and 6 min after GST] $\times 6$ $\min / 2$ ) between baseline and after 24 weeks of liraglutide treatment $\left(\triangle \mathrm{AUC}-\mathrm{CPR}=\mathrm{AUC}-\mathrm{CPR}_{24 \mathrm{weeks}}-\mathrm{AUC}\right.$ -

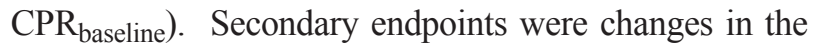
plasma glucose-adjusted $\beta$-cell function index (CPR- index $=$ CPR0 $[\mathrm{ng} / \mathrm{mL}] \times 100 / \mathrm{FPG}[\mathrm{mg} / \mathrm{dL}])[24,25]$, the ratio of the AUC-CPR to the AUC of plasma glucose (AUC-CPR/AUC-Glu) during the GST, changes in $\mathrm{HbAlc}$ levels, and changes in body weight. The homeostatic model assessment 2-\% $\% \beta$ (HOMA2- $\% \beta$ ) was calculated from FPG and fasting CPR levels using the HOMA2 calculator (version 2.2.3; downloaded from: https://www. dtu.ox.ac.uk/homacalculator/download.php) [26].

HbA1c data, measured as Japan Diabetes Society (JDS) values, were converted to National Glycohemoglobin Standardization Program (NGSP) values using the following conversion formula: HbA1c (NGSP, \%) $=1.02 \times$ HbAlc (JDS, \%) $+0.25 \%$ [27]. The eGFR was calculated using the Japan Nephrology Society equation [28].

Through the review of medical records, diabetes onset was primarily defined as the time of a new T2D diagnosis after a 75 -g oral glucose tolerance test (75g-OGTT). In cases of missing $75 \mathrm{~g}$-OGTT data, we defined T2D onset as the first detection of any of the following abnormalities, based on the American Diabetes Association Clinical Practice Recommendations 2014 [29]: (a) FPG $\geq 126 \mathrm{mg} / \mathrm{dL}$, (b) random plasma glucose $\geq 200 \mathrm{mg} / \mathrm{dL}$, or (c) HbA1c levels $\geq 6.5 \%$. Body mass index (BMI) was calculated as weight $(\mathrm{kg}) /$ height $(\mathrm{m})^{2}$ using weight and height data collected from the medical chart review.

\section{Statistical analyses}

The full analysis set was used for all endpoints. Missing data were imputed by the last observation carried forward (LOCF) method. For the primary endpoint ( $\triangle \mathrm{AUC}-\mathrm{CPR})$, statistical analysis was performed without LOCF imputation. As no previous trials have reported the effects of liraglutide on $\beta$-cell function using the GST, we based the sample size calculation on the liraglutide-related change in fasting CPR levels (mean, $0.32 \mathrm{ng} / \mathrm{mL}$ ) [17], resulting in a sample size of 60 participants to provide $90 \%$ power to detect a significant change between baseline and post-treatment values.

Values are expressed as mean \pm standard deviation (SD) for baseline characteristics (Table 1), mean \pm standard error (SE) for the results of the statistical analyses (Tables 2 to 4), or absolute values. The effects of liraglutide therapy were evaluated using paired $t$-tests or repeated measures analysis of variance (ANOVA) and post-hoc Dunnett tests. Continuous values with an asymmetric distribution are expressed as median and interquartile range and were analyzed using Wilcoxon rank sum tests. Categorical values are expressed as frequencies and percentages and were analyzed using 
Pearson's chi-square tests.

Univariate and multivariate logistic regression analyses were conducted to determine the contribution of changes in $\beta$-cell function. The $\triangle \mathrm{AUC}$-CPR was then stratified into tertiles based on T2D duration for further analyses. A receiver operating characteristic (ROC) analysis was used to define the cut-off values indicative of successful liraglutide $\beta$-cell function improvement. A two-sided $p$ value $<0.05$ was considered statistically significant. Statistical analyses were performed with JMP 11.2.1 (SAS Institute Inc., Cary, NC, USA).

This study was conducted according to the Declaration of Helsinki and was approved by the institutional review board of the Chigasaki Municipal Hospital, Kanagawa, Japan. The institutional review board waived the need for informed consent because the study involved a retrospective chart review study of regularly accumulated follow-up data.

\section{Results}

A total of 132 patients who were switched to liraglutide monotherapy after the GST were screened. Of these, 23 were excluded due to liraglutide treatment cessation due to sustained hyperglycemia, 6 due to liraglutide treatment cessation due to gastrointestinal adverse effects, and 18 patients had no GST follow-up at 24 weeks. Thus, 85 patients met the inclusion criteria. Of these, 4 were excluded because of high FPG levels at baseline ( $>180 \mathrm{mg} / \mathrm{dL}), 5$ because of a low eGFR $(<30$ $\mathrm{mL} / \mathrm{min} / 1.73 \mathrm{~m}^{2}$ ), and 3 because of malignant comorbidities, resulting in 73 patients in the full analysis set (Fig. 1). As shown in Table 1, except for diabetes duration, serum creatinine level, eGFR level, prevalence of albuminuria, and prevalence of diabetic nephropathy, the baseline characteristics were similar between the included and excluded patients. All patients were treated and followed in the outpatient clinic.

The mean age of the 73 patients was $62.2 \pm 10.2$ years, their mean T2D duration $8.2 \pm 7.2$ years, and their mean BMI $24.7 \pm 4.6 \mathrm{~kg} / \mathrm{m}^{2}$ (Table 1). While 64 patients had been treated with basal-bolus therapy without oral hypoglycemic agents, 9 had been treated with basal insulin plus metformin (with an average metformin dose of $805.5 \pm 166.7 \mathrm{mg}$ /day). Metformin was discontinued after liraglutide introduction in all patients. Regarding the insulin regimen before liraglutide introduction, 20 patients $(27 \%)$ had been treated with neutral protamine hagedorn (NPH) insulin, 10 (14\%) with insulin detemir,

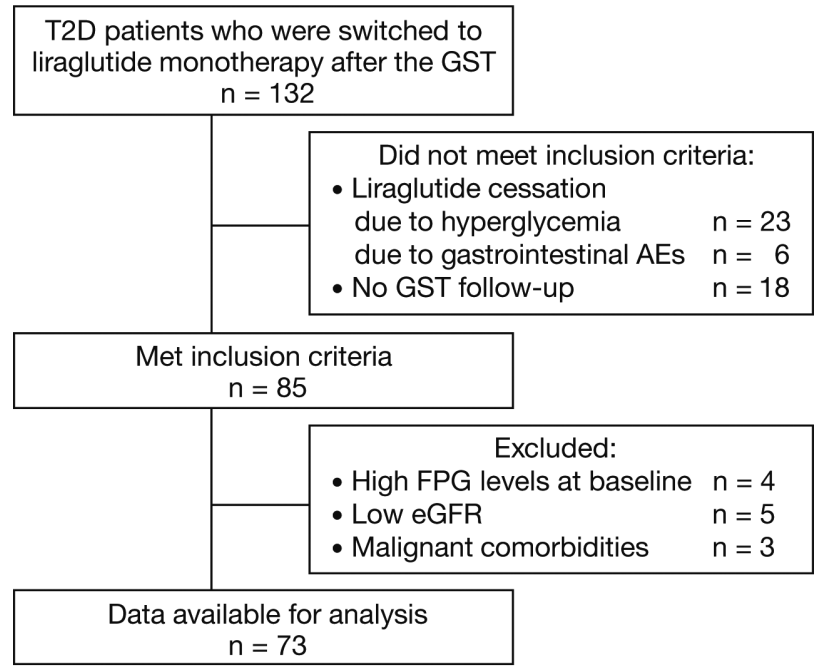

Fig. 1 Study flow chart

See text for details of the inclusion/exclusion criteria. T2D, type 2 diabetes; GST, glucagon stimulation test; AEs, adverse effects; FPG, fasting plasma glucose; eGFR, estimated glomerular filtration rate

and 43 (59\%) with insulin glargine. The percentage of patients who were treated with long-acting insulin vs. NPH insulin was not different among those in different diabetes duration tertiles $(p=0.93)$. The final dose of liraglutide was $0.89 \pm 0.05 \mathrm{mg} /$ day. There were no significant differences in the final dose between the diabetes duration tertiles $(p=0.65)$. In the full analysis set, AUCCPR levels significantly increased from $9.80 \pm 0.55 \mathrm{ng} /$ $\mathrm{mL} \cdot \min$ to $11.50 \pm 0.52 \mathrm{ng} / \mathrm{mL} \cdot \min$ after 24 weeks of liraglutide treatment $(p=0.001)$ (Table 2). CPR-index levels $(0.88 \pm 0.05$ to $1.26 \pm 0.07, p<0.001)$, HOMA2- $\% \beta$ levels $(109.7 \pm 5.8$ to $137.1 \pm 7.7, p<0.001)$, and AUCCPR/AUC-Glu levels $(0.013 \pm 0.001$ to $0.015 \pm 0.001$, $p<0.001)$ also significantly increased from baseline to 24 weeks after liraglutide treatment. HbA1c levels (7.5 $\pm 0.2 \%$ to $6.7 \pm 0.1 \%, p=0.002$ ), body weight (mean change, $-2.1 \pm 0.5 \mathrm{~kg}, p<0.001$ ), and waist circumference (mean change, $-1.8 \pm 0.9 \mathrm{~cm}, p=0.04$ ) decreased after 24 weeks of liraglutide treatment.

In the univariate regression analyses, the $\triangle \mathrm{AUC}$ CPR and T2D duration were negatively correlated (duration: $\beta=-0.22,95 \% \mathrm{CI}=-0.35$ to $-0.09, \mathrm{R}^{2}=$ $0.14, p=0.001)$ (Fig. 2, Table 3).

When the outlier of the Fig. 2 graph (right-bottom side) was eliminated, the association between diabetes duration and the $\triangle \mathrm{AUC}-\mathrm{CPR}$ was preserved $(\mathrm{n}=$ $72, \beta=-0.11,95 \% \mathrm{CI}=-0.22$ to $0.00, \mathrm{R}^{2}=0.06, p=$ 0.04 ). Of note, the association between diabetes dura- 
Table 1 Baseline clinical characteristics of patients with type 2 diabetes whose treatment was changed from insulin to liraglutide

\begin{tabular}{|c|c|c|c|}
\hline & Included $(\mathrm{n}=73)$ & Excluded $(n=59)$ & $p$ value \\
\hline Age (years) & $62.2 \pm 10.2$ & $63.1 \pm 11.0$ & 0.61 \\
\hline Sex (male/female) & $38 / 35$ & $33 / 26$ & 0.66 \\
\hline Body weight (kg) & $63.8 \pm 13.8$ & $66.8 \pm 16.1$ & 0.25 \\
\hline Body mass index $\left(\mathrm{kg} / \mathrm{m}^{2}\right)$ & $24.7 \pm 4.6$ & $25.9 \pm 5.3$ & 0.19 \\
\hline Waist circumference $(\mathrm{cm})$ & $88.6 \pm 11.1$ & $91.1 \pm 14.2$ & 0.29 \\
\hline FPG (mg/dL) & $114.4 \pm 27.2$ & $125.9 \pm 35.8$ & 0.10 \\
\hline PPG2h (mg/dL) & $170.8 \pm 49.4$ & $188.8 \pm 61.4$ & 0.07 \\
\hline HbAlc (\%) & $7.5 \pm 1.8$ & $7.8 \pm 1.7$ & 0.24 \\
\hline Type 2 diabetes duration (years) & $8.2 \pm 7.2$ & $11.6 \pm 7.9$ & 0.01 \\
\hline CPR0 (ng/mL) & $0.99 \pm 0.49$ & $1.05 \pm 0.70$ & 0.56 \\
\hline CPR6 (ng/mL) & $2.28 \pm 1.12$ & $2.28 \pm 2.09$ & 1.00 \\
\hline AUC-CPR (ng/mL·min) & $9.80 \pm 4.73$ & $9.98 \pm 8.07$ & 0.87 \\
\hline CPR-index & $0.88 \pm 0.44$ & $0.86 \pm 0.54$ & 0.83 \\
\hline HOMA2- $\% \beta$ & $109.7 \pm 49.4$ & $106.9 \pm 60.9$ & 0.77 \\
\hline AUC-CPR/AUC-Glu & $0.013 \pm 0.006$ & $0.013 \pm 0.011$ & 0.61 \\
\hline \multicolumn{4}{|l|}{ Insulin therapy regimen } \\
\hline Basal-bolus therapy without OHAs (n, (\%)) & $64(88)$ & $45(76)$ & \multirow{2}{*}{0.09} \\
\hline Basal insulin plus metformin $(\mathrm{n},(\%))$ & $9(12)$ & $14(24)$ & \\
\hline Total insulin dose (units/kg/day) & $0.34 \pm 0.17$ & $0.41 \pm 0.23$ & 0.05 \\
\hline Basal insulin dose (units/kg/day) & $0.15 \pm 0.09$ & $0.19 \pm 0.11$ & 0.06 \\
\hline Long-acting insulin use $(\mathrm{n},(\%))$ & $53(73)$ & $44(75)$ & \multirow{2}{*}{0.80} \\
\hline Neutral Protamine Hagedorn insulin use (n, $(\%))$ & $20(27)$ & $15(25)$ & \\
\hline Serum creatinine $(\mathrm{mg} / \mathrm{dL})$ & $0.79 \pm 0.17$ & $1.13 \pm 1.30$ & 0.003 \\
\hline $\operatorname{eGFR}\left(\mathrm{mL} / \mathrm{min} / 1.73 \mathrm{~m}^{2}\right)$ & $70.4 \pm 17.7$ & $58.9 \pm 21.8$ & 0.001 \\
\hline Albuminuria (mg/g-creatinine, [IQR]) & $10.3[5.9,19.7]$ & $22.0[10.3,60.2]$ & $<0.001$ \\
\hline Normoalbuminuria $(\mathrm{n},(\%))$ & $60(82)$ & $36(61)$ & \\
\hline Microalbuminuria (n, (\%)) & $10(14)$ & $18(31)$ & 0.02 \\
\hline Macroalbuminuria (n, (\%)) & $3(4)$ & $5(8)$ & \\
\hline \multicolumn{4}{|l|}{ Diabetic retinopathy } \\
\hline No diabetic retinopathy $(\mathrm{n},(\%))$ & $57(78)$ & $39(66)$ & \multirow{3}{*}{0.23} \\
\hline Nonproliferative retinopathy $(\mathrm{n},(\%))$ & $13(18)$ & $14(24)$ & \\
\hline Proliferative retinopathy $(\mathrm{n},(\%))$ & $3(4)$ & $6(10)$ & \\
\hline Diabetic neuropathy $(\mathrm{n},(\%))$ & $21(29)$ & $25(42)$ & 0.10 \\
\hline
\end{tabular}

Data are expressed as number or mean \pm standard deviation (SD), median and interquartile range [IQR], or absolute value (percentage). $p$ values were determined using $t$-tests, Chi-square tests, or Wilcoxon rank sum tests. AUC, area under the curve; AUC-CPR, (CPR0 + CPR6) $\times 6 \mathrm{~min} / 2$; AUC-Glu, $(\mathrm{FPG}+$ plasma glucose 6 min after glucagon stimulation $) \times 6 \mathrm{~min} / 2$; CPR, serum C-peptide level; CPR0, fasting serum C-peptide level; CPR6, serum C-peptide level 6 min after glucagon stimulation; CPR-index, CPR0 × 100/FPG; OHA, oral hypoglycemic agents; eGFR, estimated glomerular filtration rate; FPG, fasting plasma glucose; IQR, interquartile range; HOMA-2\%, homeostatic model assessment 2-\% $\beta$; PPG2h, 2 h-postprandial plasma glucose.

Table 2 Changes in variables over the 24-week period of liraglutide treatment in patients with type 2 diabetes $(n=73)$

\begin{tabular}{lccccc}
\hline & Baseline & 12 weeks & 24 weeks & Change* $(95 \%$ CI) & $p$ value \\
\hline AUC-CPR $(\mathrm{ng} / \mathrm{mL} \cdot \mathrm{min})$ & $9.80 \pm 0.55$ & & $11.50 \pm 0.52$ & $+1.70 \pm 0.49(0.72$ to 2.69$)$ & 0.001 \\
CPR-index & $0.88 \pm 0.05$ & & $1.26 \pm 0.07$ & $+0.38 \pm 0.05(0.29$ to 0.50$)$ & $<0.001$ \\
HOMA2-\% $\beta$ & $109.7 \pm 5.8$ & & $137.1 \pm 7.7$ & $+27.4 \pm 6.1(14.2$ to 35.7$)$ & $<0.001$ \\
AUC-CPR/AUC-Glu & $0.013 \pm 0.001$ & & $0.015 \pm 0.001$ & $+0.002 \pm 0.001(0.001$ to 0.003$)$ & $<0.001$ \\
CPR0 $(\mathrm{ng} / \mathrm{mL})$ & $0.99 \pm 0.06$ & & $1.48 \pm 0.07$ & $+0.50 \pm 0.07(0.36$ to 0.63$)$ & $<0.001$ \\
CPR6 $(\mathrm{ng} / \mathrm{mL})$ & $2.28 \pm 0.13$ & & $2.35 \pm 0.11$ & $+0.07 \pm 0.11(-0.14$ to 0.28$)$ & 0.51 \\
HbA1c $(\%)$ & $7.5 \pm 0.2$ & $6.5 \pm 0.1^{\dagger}$ & $6.7 \pm 0.1^{\dagger}$ & $-0.7 \pm 0.2(-1.2$ to -0.3$)$ & 0.002 \\
FPG $(\mathrm{mg} / \mathrm{dL})$ & $114.4 \pm 3.2$ & $121.5 \pm 2.9^{\dagger}$ & $122.1 \pm 3.2$ & $+7.8 \pm 3.9(-0.1$ to 15.6$)$ & 0.05 \\
PPG2h $(\mathrm{mg} / \mathrm{dL})$ & $170.8 \pm 5.8$ & $149.6 \pm 4.9^{\dagger}$ & $147.1 \pm 5.1^{\dagger}$ & $-23.7 \pm 5.5(-34.7$ to -12.7$)$ & 0.001 \\
Body weight $(\mathrm{kg})$ & $63.8 \pm 1.6$ & $61.6 \pm 1.6^{\dagger}$ & $61.6 \pm 1.7^{\dagger}$ & $-2.1 \pm 0.5(-3.1$ to -1.2$)$ & $<0.001$ \\
Waist circumference $(\mathrm{cm})$ & $88.6 \pm 1.3$ & $85.1 \pm 1.2^{\dagger}$ & $86.9 \pm 1.3^{\dagger}$ & $-1.8 \pm 0.9(-3.5$ to 0.0$)$ & 0.04 \\
\hline
\end{tabular}

Data are expressed as number or mean \pm standard error (SE). ${ }^{*}$ Change was determined between 24 weeks and baseline. $P$ values were determined by paired $t$-tests or repeated measures ANOVA and post-hoc Dunnett tests $v s$. baseline, ${ }^{\dagger} p<0.05 v s$. baseline. AUC, area under the curve; AUC-CPR, (CPR0 + CPR6) $\times 6 \mathrm{~min} / 2$; CI, confidence interval; CPR, serum C-peptide level; CPR-index, fasting serum C-peptide level $\times 100$ /fasting plasma glucose; CPR0, fasting serum C-peptide level; CPR6, serum C-peptide level 6 min after glucagon stimulation; FPG, fasting plasma glucose; HOMA-2\%, homeostatic model assessment 2-\% $\beta$; PPG2h, 2 h-postprandial plasma glucose. 


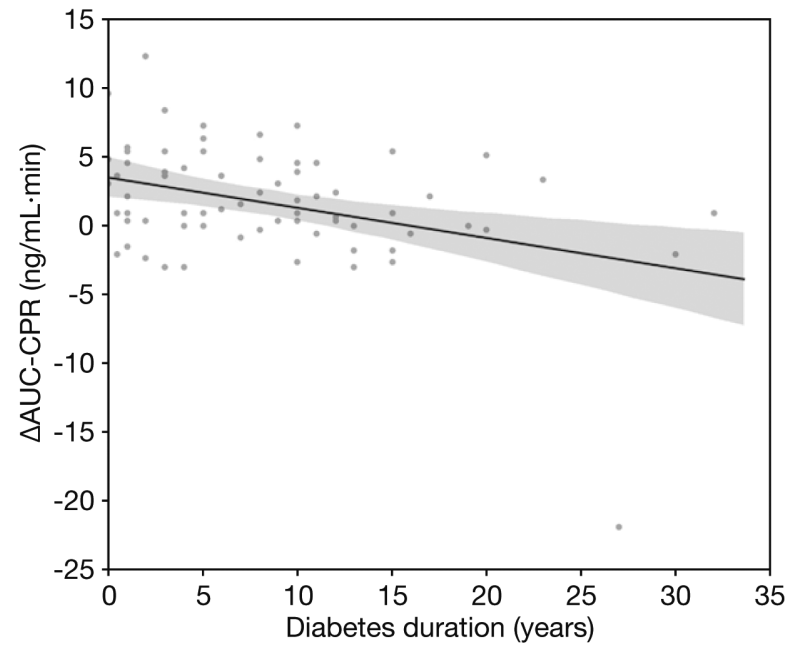

Fig. 2 Relationship between diabetes duration and the $\triangle \mathrm{AUC}$ CPR in patients with type 2 diabetes treated with liraglutide The univariate regression analysis showed a negative correlation between the $\triangle \mathrm{AUC}-\mathrm{CPR}$ and diabetes duration $(\beta=-0.22,95 \%$ confidence interval $[\mathrm{CI}]=-0.35$ to -0.09 , $\left.\mathrm{R}^{2}=0.14, p=0.001\right)$. The grey area shows the $95 \% \mathrm{CI}$ around the regression line. AUC, area under the curve; $\triangle \mathrm{AUC}-\mathrm{CPR}$, change in the AUC of C-peptide levels during the glucagon stimulation test (AUC-CPR) from baseline to 24 weeks of liraglutide treatment. tion and the $\triangle \mathrm{AUC}-\mathrm{CPR} / \mathrm{AUC}-\mathrm{Glu}$ was also maintained after the outlier was eliminated $\left(\beta=-1.29 \times 10^{-4}\right.$, $95 \% \mathrm{CI}=-2.44 \times 10^{-4}$ to $-1.36 \times 10^{-5}, \mathrm{R}^{2}=0.07, p=0.03$ ) (Supplementary Fig. 1).

In the multivariate regression model, the effect of T2D duration on the $\triangle \mathrm{AUC}-\mathrm{CPR}$ was present even after adjusting for age, sex, changes in body weight, changes in $\mathrm{HbAlc}$ levels, basal insulin dose, and long-acting insulin use (duration: $\beta=-0.20,95 \% \mathrm{CI}=-0.34$ to -0.05 , $\left.\mathrm{R}^{2}=0.23, p=0.008\right)$. In the analysis using $\mathrm{T} 2 \mathrm{D}$ duration tertiles, patients who initiated liraglutide treatment within 10 years of their T2D diagnosis had significantly improved AUC-CPR values (duration $<4$ years: $+2.56 \pm$ $0.73 \mathrm{ng} / \mathrm{mL} \cdot \min , p=0.002$; duration, $4-10$ years: +2.60 $\pm 0.56 \mathrm{ng} / \mathrm{mL} \cdot \min , p<0.001)$, whereas patients who initiated liraglutide treatment $>10$ years after the T2D diagnosis did not $(-0.33 \pm 1.15 \mathrm{ng} / \mathrm{mL} \cdot \min , p=0.78)$ (Table 4). The ROC analysis revealed that a T2D duration cut-off value of 10 years had $77 \%$ sensitivity, $50 \%$ specificity, a positive predictive value of $80 \%$, and negative predictive value of $45 \%$ for a positive effect of liraglutide on the $\triangle \mathrm{AUC}-\mathrm{CPR}$ (Fig. 3).

Table 3 Linear regression analysis of the $\triangle$ AUC-CPR and demographic and clinical variables in patients with type 2 diabetes treated with liraglutide

\begin{tabular}{|c|c|c|c|c|c|c|c|c|}
\hline & \multicolumn{4}{|c|}{ Univariate regression model } & \multicolumn{4}{|c|}{ Multivariate regression model } \\
\hline & $\beta$ & SE & $95 \% \mathrm{CI}$ & $p$ value & $\beta$ & SE & $95 \% \mathrm{CI}$ & $p$ value \\
\hline Type 2 diabetes duration (years) & -0.22 & 0.06 & -0.35 to -0.09 & 0.001 & -0.20 & 0.07 & -0.34 to -0.05 & 0.008 \\
\hline Age (years) & -0.05 & 0.05 & -0.18 to 0.05 & 0.30 & 0.02 & 0.05 & -0.09 to 0.12 & 0.76 \\
\hline Male sex & 0.44 & 1.00 & -1.55 to 2.42 & 0.66 & 0.29 & 0.51 & -0.74 to 1.32 & 0.58 \\
\hline Change in body weight (kg) & 0.28 & 0.11 & 0.05 to 0.51 & 0.02 & 0.18 & 0.12 & -0.06 to 0.43 & 0.15 \\
\hline Change in HbAlc levels (\%) & -0.54 & 0.26 & -1.05 to -0.02 & 0.04 & -0.32 & 0.28 & -0.88 to 0.24 & 0.26 \\
\hline Basal insulin dose (units/kg/day) & 4.03 & 5.47 & -6.88 to 14.93 & 0.46 & 10.20 & 5.73 & -1.25 to 21.66 & 0.08 \\
\hline Long-acting insulin use & 0.98 & 1.11 & -1.24 to 3.20 & 0.38 & 0.12 & 0.55 & -0.98 to 1.22 & 0.83 \\
\hline
\end{tabular}

In the multiple regression model, the effect of diabetes duration on the $\triangle \mathrm{AUC}-\mathrm{CPR}$ was adjusted for age, sex, change in body weight, changes in HbA1c levels, basal insulin dose, and long-acting insulin use. AUC, area under the curve; $\triangle \mathrm{AUC}-\mathrm{CPR}$, change in the AUC of C-peptide levels during the glucagon stimulation test (AUC-CPR) from baseline to 24 weeks of liraglutide treatment; CI, confidence interval; SE, standard error.

Table 4 Analysis of the $\triangle$ AUC-CPR by diabetes duration tertiles in patients with type 2 diabetes treated with liraglutide

\begin{tabular}{lccc}
\hline & Tertile 1 $(\mathrm{n}=27)$ & Tertile 2 $(\mathrm{n}=24)$ & Tertile 3 $(\mathrm{n}=22)$ \\
\hline Type 2 diabetes duration (years) & $<4$ & $4-10$ & $>10$ \\
Baseline AUC-CPR $(\mathrm{ng} / \mathrm{mL} \cdot \mathrm{min})$ & $9.80 \pm 1.05$ & $8.96 \pm 0.60$ & $10.70 \pm 1.14$ \\
24-week AUC-CPR $(\mathrm{ng} / \mathrm{mL} \cdot \mathrm{min})$ & $12.36 \pm 1.03$ & $11.56 \pm 0.61$ & $10.37 \pm 0.97$ \\
$\Delta$ AUC-CPR $(\mathrm{ng} / \mathrm{mL} \cdot \mathrm{min})$ & $2.56 \pm 0.73$ & $2.60 \pm 0.56$ & $-0.33 \pm 1.15^{\dagger}$ \\
Changes in HbAlc levels from baseline (\%) & $-1.03 \pm 0.36$ & $-0.88 \pm 0.38$ & $-0.16 \pm 0.40$ \\
Long-acting insulin use before liraglutide introduction (n, (\%)) & $19(70)$ & $18(75)$ & $16(73)$ \\
$p$ value & 0.002 & $<0.001$ & 0.78 \\
\hline
\end{tabular}

Data are expressed as mean \pm standard error (SE) or absolute value (percentage). $P$ values were determined by paired $t$-tests between the AUC-CPR at baseline and at 24 weeks, and ${ }^{\dagger} p<0.05$ was determined by the Dunnett test $v s$. tertile 1 . AUC, area under the curve; $\triangle \mathrm{AUC}-\mathrm{CPR}$, change in the AUC of C-peptide levels during the glucagon stimulation test (AUC-CPR) from baseline to 24 weeks of liraglutide treatment; AUC-CPR, (CPR0 + CPR6) × 6 min/2; CPR, serum C-peptide level; CPR0, fasting serum C-peptide level; CPR6, serum C-peptide level 6 min after glucagon stimulation. 


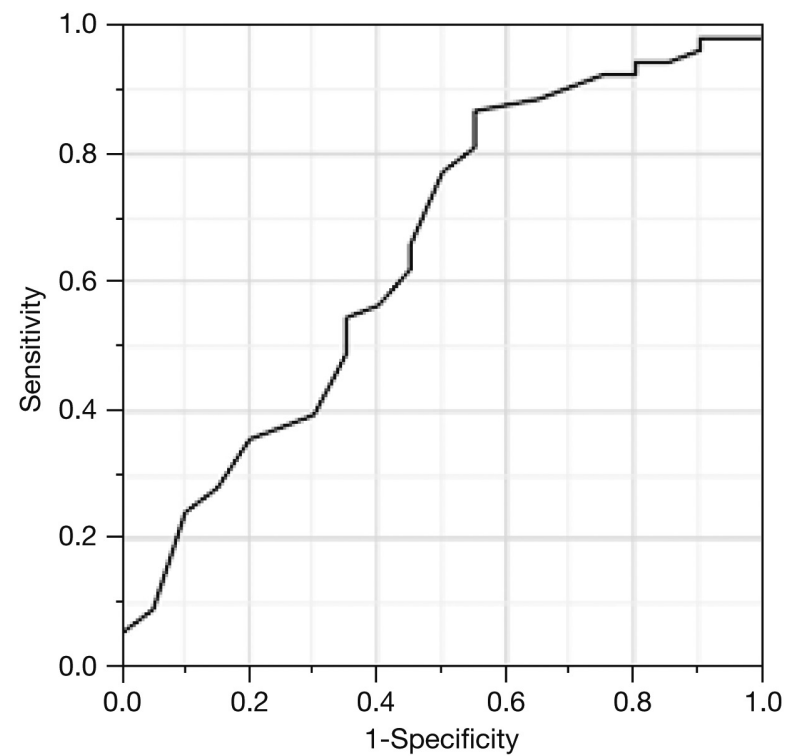

Fig. 3 Receiver operating curve (ROC) analysis of a positive $\triangle$ AUC-CPR and diabetes duration in patients with type 2 diabetes treated with liraglutide

Liraglutide improved $\beta$-cell function in patients with a diabetes duration $<10$ years. The cut-off value of 10 years had $77 \%$ sensitivity, $50 \%$ specificity, a positive predictive value of $80 \%$, and a negative predictive value of $45 \%$. The area under the curve was 0.65 . AUC, area under the curve; $\triangle \mathrm{AUC}-\mathrm{CPR}$, change in the AUC of C-peptide levels during the glucagon stimulation test (AUC-CPR) from baseline to 24 weeks of liraglutide treatment.

\section{Discussion}

Twenty-four weeks of liraglutide treatment improved not only the AUC-CPR but also plasma glucose-adjusted indices, such as the CPR-index, HOMA2-\% $\beta$, and the AUC-CPR/AUC-Glu. The AUC-CPR increased by $1.70 \mathrm{ng} / \mathrm{mL} \cdot \mathrm{min}$, and we found a significant reduction in $\mathrm{HbA} 1 \mathrm{c}$ levels and a positive effect on $\beta$-cell function despite the limited liraglutide dose $(0.9 \mathrm{mg} /$ day $)$.

CPR0 but not CPR6 levels improved after liraglutide treatment. This effect of liraglutide on basal insulin secretion is consistent with the results of several preclinical studies $[16,17]$. Although fasting plasma glucose levels did not significantly change in our study, CPR0 levels did improve after liraglutide treatment. This effect can be considered as an improvement of the insulin release responsiveness to glucose (glucose sensitivity of $\beta$ cells). The $\beta$-cell threshold sensitivity to glucose is correlated to glucokinase gene expression [30]. Exenatide, belonging to another class of GLP-1 receptor agonists, is known to increase glucokinase protein expression [31]. Shirakawa et al. also reported that $\beta$-cell glucokinase appears to be essential for liraglutide-mediated insulin secretion [32]. Collectively, these results suggest that liraglutide enhanced the glucose sensitivity of $\beta$-cells through glucokinase activation, resulting in improved CPR0 levels.

Although early insulin treatment is known to have a protective effect on $\beta$-cell function [33-36], to the best of our knowledge, this is the first study to examine the interaction between the effect of liraglutide on $\beta$-cell function and T2D duration in a clinical setting. Better outcomes of liraglutide therapy in patients with shorter diabetes durations have been documented in previous reports focusing on residual $\beta$-cell function and the effectiveness of liraglutide for lowering glucose levels [7-9]. In addition, exenatide has been reported to improve $\beta$-cell function in newly or recently diagnosed patients with T2D [37-39]. Therefore, the early use of a GLP-1 receptor agonist might be a key factor for the positive effect on $\beta$-cell function. The findings of the present study support that early initiation of liraglutide therapy (T2D duration $\leq 10$ years) improves $\beta$-cell function, whereas late liraglutide initiation (T2D duration $>10$ years) does not. Multiple preclinical studies have shown that liraglutide expands $\beta$-cell mass in rodent models. In a db/db mouse model, early liraglutide treatment resulted in greater improvements of $\beta$-cell function and preservation of a greater $\beta$-cell mass [40]. Early introduction of liraglutide also resulted in a higher expression of proliferation-related genes (pancreatic and duodenal homeobox 1 [PDX-1] and MafA) [41]. GLP-1-responsive $\beta$-cell replication is substantially diminished in older people [42]; therefore, introduction of liraglutide in the early disease stages is likely important for $\beta$-cell function.

Treatment with liraglutide resulted in significant decreases in body weight in the present study. Although it has been reported that weight reduction also improves $\beta$-cell function [43, 44], the effect of liraglutide on $\beta$-cell function was independent of body weight in the multiple regression model in the present study. Maeda et al. reported that short diabetes duration and a low BMI are predictive for the efficacy of dipeptidyl peptidase-4 (DPP-4) inhibitors in Japanese T2D patients [45]. However, as shown in Table 4, $\mathrm{HbA} 1 \mathrm{c}$ levels tended to show greater changes from baseline in the shorter diabetes duration tertile (tertile $1)$, which was not statistically significant in our analysis $(p=0.25)$. These changes were also independent of the BMI in our univariate regression analysis $(\beta=0.02$, 
$\mathrm{SE}=0.05,95 \% \mathrm{CI}=-0.08$ to $0.12, p=0.68)$. These differences between our findings and those of Maeda et al. regarding the relationship between BMI and reduction in $\mathrm{HbAlc}$ might be the result of treatment differences at baseline; while Maeda et al. added the DPP-4 inhibitor sitagliptin to ongoing non-insulin treatment [45], patients were treated with insulin therapy before the liraglutide treatment in the present study. Second, the effects of DPP-4 inhibitors depend on endogenous GLP-1 levels, which are inversely correlated with BMI [46]. GLP-1 receptor agonists enhance exogenous GLP-1 levels, and their effect depends on residual $\beta$-cell function rather than endogenous GLP-1 levels. In the present study, BMI and HOMA2- $\% \beta$ were related in the univariate regression analysis $(\beta=5.05$, $\mathrm{SE}=1.12,95 \% \mathrm{CI}=2.81$ to $7.29, p<0.001)$. These differences in action potentially explain the differences in the relationship between BMI and reduction in $\mathrm{HbA} 1 \mathrm{c}$ between DPP4 inhibitors and liraglutide.

This study has certain limitations. First, owing to the retrospective nature of the study, more robust study designs such as placebo-controlled randomized controlled trials and meta-analyses should be used in future studies to confirm the plausible effect of liraglutide on $\beta$-cell function. However, because the effect of T2D duration on $\beta$-cell function with liraglutide treatment was preserved even after adjusting for several possible confounders, we believe that our results are valid. In addition, our GST-based results are consistent with those of Retnakaran et al. in their Liraglutide and Beta-cell Repair Study (LIBRA), in which liraglutide enhanced $\beta$-cell function as assessed by the insulin secretion sensitivity index-2 with OGTT in patients with early T2D (mean T2D duration, $2.6 \pm 1.9$ years) [47].

Second, $45 \%$ of the patients were excluded from the final analysis based on screening of the data for the inclusion/exclusion criteria to avoid inappropriate assessment of $\beta$-cell function and the selection bias was considered to be within an acceptable range. There were differences in diabetes duration and diabetic nephropathy related items between the included and excluded patients. Diabetes duration was significantly related with eGFR in the univariate regression analysis $(\beta=-0.63, \mathrm{SE}=0.22,95 \% \mathrm{CI}$ $=-1.09$ to $-0.18, p=0.007)$.

Third, we included patients who had been treated with insulin prior to the introduction of liraglutide to eliminate the potential effect of glucotoxicity on the assessment of $\beta$-cell function. The prior use of insulin therapy, especially long-acting insulin such as insulin glargine has been reported to influence fasting C-peptide levels $[48,49]$ and therefore could have affected $\beta$-cell function, as assessed by the AUC-CPR. However, our univariate regression analysis indicated that the basal insulin dose and long-acting insulin use before liraglutide introduction did not affect the $\triangle$ AUC-CPR. Even after adjusting for basal insulin dose and long-acting insulin use prior to liraglutide introduction in our multivariate regression model, the negative effect of diabetes duration on the $\triangle \mathrm{AUC}-\mathrm{CPR}$ was preserved (Table 3).

Fourth, metformin cessation in 9 patients $(12 \%)$ could have caused changes in $\beta$-cell function, as metformin has been reported to improve $\beta$-cell function [50]. However, when taking the negative effect of metformin cessation into account, liraglutide improved the $\triangle$ AUC-CPR in patients with T2D. Finally, defining T2D onset is difficult owing to the varying intervals from onset to diagnosis between individuals. However, since more than half of the patients (56\%) were diagnosed with T2D during an annual medical check-up or regular outpatient follow-up, their onset-to-diagnosis lag time should be relatively short.

In conclusion, our findings suggest that early liraglutide treatment potentially improves $\beta$-cell function in patients with T2D. This should help prevent the naturally occurring decline in $\beta$-cell function, improve glycemic control, and delay the progression of diabetic complications. However, further long-term observational studies are warranted to confirm our findings.

\section{Acknowledgments}

This work was supported in part by Grants-in-Aid for Scientific Research (B) 21390282 and (B) 24390235 from the Ministry of Education, Culture, Sports, Science and Technology (MEXT) of Japan; a Medical Award from the Japan Medical Association; and a Grant-inAid from the Japan Diabetes Foundation. Part of this study was presented in general poster session form at the $73^{\text {rd }}$ Scientific Sessions of the American Diabetes Association, Chicago, Illinois, 22-23 June 2013.

\section{Disclosure}

Kondo Y. declares no conflicts of interest. Satoh S. declares no conflicts of interest. Osada UN. declares no conflicts of interest. Terauchi Y received unrestricted grants from MSD; 
Ono Pharmaceutical Co. Ltd.; Boehringer Ingelheim GmbH; Novartis Pharma; Takeda Pharmaceutical Company Ltd.; Tanabe-Mitsubishi Pharma; DaiichiSankyo Company Ltd.; Sanwa Kagaku Kenkyusho Co., Ltd.; Kowa Pharmaceutical Co., Ltd.; Novo Nordisk Pharma Ltd.; Eli Lilly and Company; Sanofi, DaiNipponSumitomo, Shionogi \& Co.; Ltd., Kissei, Bayer Yakuhin Ltd., Astellas Pharma Inc.; and Astra Zeneca.

Terauchi Y received honoraria for lectures from MSD; Ono Pharmaceutical Co. Ltd.; Boehringer Ingelheim
GmbH; Novartis Pharma; Takeda Pharmaceutical Company Ltd.; Tanabe-Mitsubishi Pharma; DaiichiSankyo Company Ltd.; Sanwa Kagaku Kenkyusho Co., Ltd.; Kowa Pharmaceutical Co., Ltd.; Novo Nordisk Pharma Ltd.; Eli Lilly and Company; Sanofi, DaiNippon-Sumitomo, Shionogi \& Co., Ltd.; Kissei, Bayer Yakuhin Ltd.; Astellas Pharma Inc.; Pfizer; Astra Zeneca; Chugai Pharmaceutical Co., Ltd.; Teijin; Mochida Pharmaceutical Co. Ltd.; Roche Diagnostics; and Johnson \& Johnson.
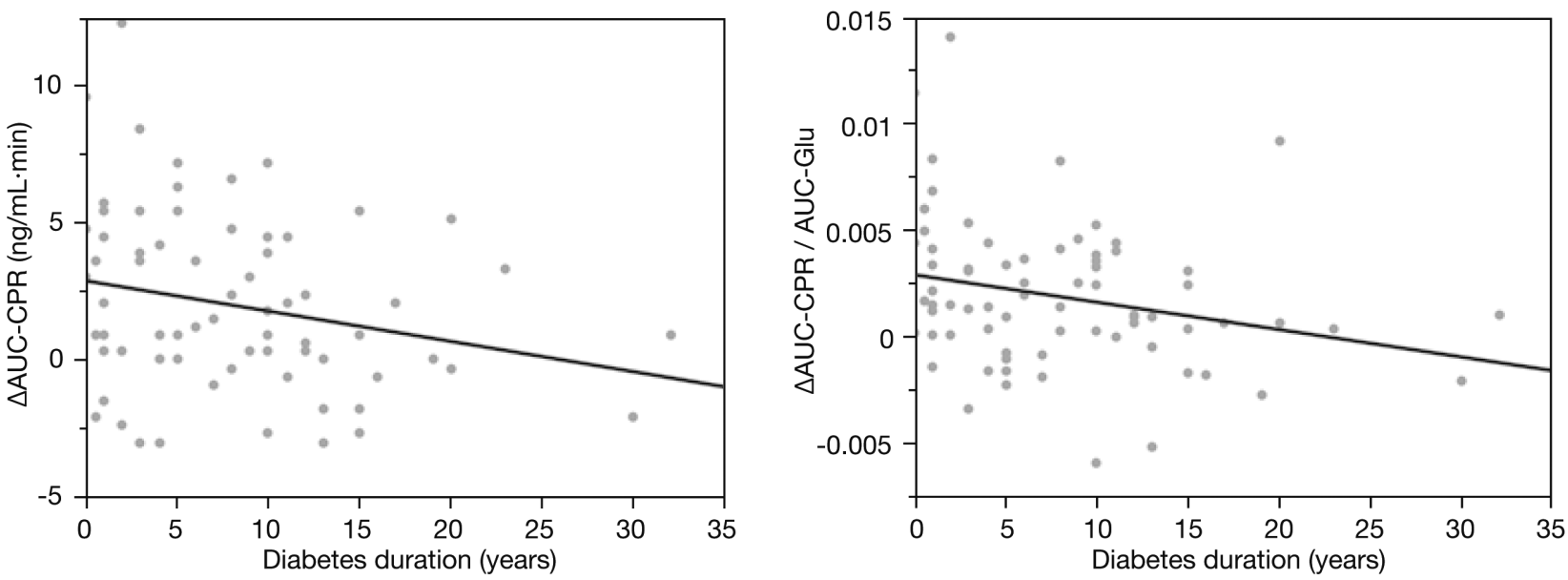

Supplementary Fig. 1 Association between diabetes duration and the $\triangle$ AUC-CPR and $\triangle$ AUC-CPR/AUC-Glu in patients with type 2 diabetes treated with liraglutide (without outlier, $\mathrm{n}=72$ ). When the outlier of the Figure 2 graph (rightbottom side) was eliminated, the relationship between diabetes duration and the $\triangle \mathrm{AUC}$-CPR was preserved in the univariate regression model analysis $\left(\beta=-0.11,95 \%\right.$ confidence interval $[\mathrm{CI}]=-0.22$ to $0.00, \mathrm{R}^{2}=0.06, p$ $=0.04)$. The association between diabetes duration and the $\triangle$ AUC-CPR/AUC-Glu was also maintained after the outlier was eliminated $\left(\beta=-1.29 \times 10^{-4}, 95 \% \mathrm{CI}=-2.44 \times 10^{-4}\right.$ to $\left.-1.36 \times 10^{-5}, \mathrm{R}^{2}=0.07, p=0.03\right)$. AUC, area under the curve; $\triangle \mathrm{AUC}-\mathrm{CPR}$, change in the AUC of C-peptide levels during the glucagon stimulation test (AUC-CPR) from baseline to 24 weeks of liraglutide treatment; AUC-Glu, (fasting plasma glucose + plasma glucose $6 \mathrm{~min}$ after glucagon stimulation) $\times 6 \mathrm{~min} / 2$

\section{References}

1. U.K. Prospective Diabetes Study Group (1995) U.K. Prospective Diabetes Study 16: Overview of 6 Years' Therapy of Type II Diabetes: A Progressive Disease. Diabetes 44: 1249-1258.

2. Bo S, Cavallo-Perin P, Gentile L, Repetti E, Pagano G (2000) Relationship of residual beta-cell function, metabolic control and chronic complications in type 2 diabetes mellitus. Acta Diabetol 37: 125-129.

3. Bo S, Gentile L, Castiglione A, Prandi V, Canil S, et al. (2012) C-peptide and the risk for incident complications and mortality in type 2 diabetic patients: a retrospective cohort study after a 14-year follow-up. Eur $J$ Endocrinol 167: 173-180.

4. Butler AE, Janson J, Bonner-Weir S, Ritzel R, Rizza RA, et al. (2003) Beta-cell deficit and increased beta- cell apoptosis in humans with type 2 diabetes. Diabetes 52: $102-110$.

5. Butler AE, Janson J, Soeller WC, Butler PC (2003) Increased beta-cell apoptosis prevents adaptive increase in beta-cell mass in mouse model of type 2 diabetes: evidence for role of islet amyloid formation rather than direct action of amyloid. Diabetes 52: 2304-2314.

6. Blonde L, Russell-Jones D (2009) The safety and efficacy of liraglutide with or without oral antidiabetic drug therapy in type 2 diabetes: an overview of the LEAD 1-5 studies. Diabetes Obes Metab 11 Suppl 3: 26-34.

7. Kozawa J, Inoue K, Iwamoto R, Kurashiki Y, Okauchi $\mathrm{Y}$, et al. (2012) Liraglutide is effective in type 2 diabetic patients with sustained endogenous insulin secreting capacity. J Diabetes Investig 3: 294-297. 
8. Iwao T, Sakai K, Sata M (2013) Postprandial serum $\mathrm{C}$-peptide is a useful parameter in the prediction of successful switching to liraglutide monotherapy from complex insulin therapy in Japanese patients with type 2 diabetes. J Diabetes Complications 27: 87-91.

9. Kondo Y, Satoh S, Nagakura J, Kimura M, Nezu U, et al. (2013) Defining criteria for the introduction of liraglutide using the glucagon stimulation test in patients with type 2 diabetes. J Diabetes Investig 4: 571-575.

10. Usui R, Yabe D, Kuwata H, Fujiwara S, Watanabe K, et al. (2013) Retrospective analysis of safety and efficacy of insulin-to-liraglutide switch in Japanese type 2 diabetes: A caution against inappropriate use in patients with reduced $\beta$-cell function. J Diabetes Investig 4: 585-594.

11. Drucker DJ (2006) The biology of incretin hormones. Cell Metab 3: 153-165.

12. Farilla L, Bulotta A, Hirshberg B, Li Calzi S, Khoury N, et al. (2003) Glucagon-Like Peptide 1 Inhibits Cell Apoptosis and Improves Glucose Responsiveness of Freshly Isolated Human Islets. Endocrinology 144: 5149-5158.

13. Degn KB, Juhl CB, Sturis J, Jakobsen G, Brock B, et al. (2004) One week's treatment with the long-acting glucagon-like peptide 1 derivative liraglutide (NN2211) markedly improves 24-h glycemia and alpha- and betacell function and reduces endogenous glucose release in patients with type 2 diabetes. Diabetes 53: 1187-1194.

14. Toso C, McCall M, Emamaullee J, Merani S, Davis J, et al. (2010) Liraglutide, a long-acting human glucagonlike peptide 1 analogue, improves human islet survival in culture. Transpl Int 23: 259-265.

15. Shimoda M, Kanda Y, Hamamoto S, Tawaramoto K, Hashiramoto M, et al. (2011) The human glucagon-like peptide-1 analogue liraglutide preserves pancreatic beta cells via regulation of cell kinetics and suppression of oxidative and endoplasmic reticulum stress in a mouse model of diabetes. Diabetologia 54: 1098-1108.

16. Zinman B, Gerich J, Buse JB, Lewin A, Schwartz S, et al. (2009) Efficacy and safety of the human glucagonlike peptide-1 analog liraglutide in combination with metformin and thiazolidinedione in patients with type 2 diabetes (LEAD-4 Met+TZD). Diabetes Care 32: 1224-1230.

17. Seino Y, Rasmussen MF, Clauson P, Kaku K (2012) The once daily human glucagon like peptide 1 analog, liraglutide, improves $\beta$ cell function in Japanese patients with type 2 diabetes. J Diabetes Investig 3: 388-395.

18. Vilsbøll T, Brock B, Perrild H, Levin K, Lervang HH, et al. (2008) Liraglutide, a once-daily human GLP-1 analogue, improves pancreatic B-cell function and arginine-stimulated insulin secretion during hyperglycaemia in patients with Type 2 diabetes mellitus. Diabet Med 25: 152-156.

19. Takabe M, Matsuda T, Hirota Y, Hashimoto N, Nakamura T, et al. (2012) C-peptide response to gluca- gon challenge is correlated with improvement of early insulin secretion by liraglutide treatment. Diabetes Res Clin Pract 98: e32-e35.

20. Faber OK, Binder C (1977) C-peptide response to glucagon. A test for the residual beta-cell function in diabetes mellitus. Diabetes 26: 605-610.

21. Hendriksen C, Faber OK, Drejer J, Binder C (1977) Prevalence of residual B-cell function in insulin-treated diabetics evaluated by the plasma C-peptide response to intravenous glucagon. Diabetologia 13: 615-619.

22. Gjessing HJ, Damsgaard EM, Matzen LE, Frøland A, Faber OK (1987) Reproducibility of beta-cell function estimates in non-insulin-dependent diabetes mellitus. Diabetes Care 10: 558-562.

23. Kawai K, Yokota C, Ohashi S, Watanabe Y, Yamashita K (1995) Evidence that glucagon stimulates insulin secretion through its own receptor in rats. Diabetologia 38: 274-276.

24. Meier JJ, Menge BA, Breuer TG, Müller CA, Tannapfel A, et al. (2009) Functional assessment of pancreatic beta-cell area in humans. Diabetes 58: 1595-1603.

25. Funakoshi S, Fujimoto S, Hamasaki A, Fujiwara H, Fujita Y, et al. (2011) Utility of indices using C-peptide levels for indication of insulin therapy to achieve good glycemic control in Japanese patients with type 2 diabetes. J Diabetes Investig 2: 297-303.

26. Levy JC, Matthews DR, Hermans MP (1998) Correct homeostasis model assessment (HOMA) evaluation uses the computer program. Diabetes Care 21: 21912192 .

27. Kashiwagi A, Kasuga M, Araki E, Oka Y, Hanafusa $\mathrm{T}$, et al. (2012) International clinical harmonization of glycated hemoglobin in Japan: From Japan Diabetes Society to National Glycohemoglobin Standardization Program values. J Diabetes Investig 3: 39-40.

28. Matsuo S, Imai E, Horio M, Yasuda Y, Tomita K, et al. (2009) Revised equations for estimated GFR from serum creatinine in Japan. Am J Kidney Dis 53: 982992.

29. American Diabetes Association (2014) Standards of medical care in diabetes--2014. Diabetes Care 37 Suppl 1: S14-S80.

30. Schuit FC (1996) Factors determining the glucose sensitivity and glucose responsiveness of pancreatic beta cells. Horm Res 46: 99-106.

31. Murao K, Li J, Imachi H, Muraoka T, Masugata H, et al. (2009) Exendin-4 regulates glucokinase expression by CaMKK/CaMKIV pathway in pancreatic beta-cell line. Diabetes Obes Metab 11: 939-946.

32. Shirakawa J, Tanami R, Togashi Y, Tajima K, Orime K, et al. (2012) Effects of liraglutide on $\beta$-cell-specific glucokinase-deficient neonatal mice. Endocrinology 153: 3066-3075.

33. Weng J, Li Y, Xu W, Shi L, Zhang Q, et al. (2008) Effect of intensive insulin therapy on $\beta$-cell function and gly- 
caemic control in patients with newly diagnosed type 2 diabetes: a multicentre randomised parallel-group trial. Lancet 371: 1753-1760.

34. Chen HS, Wu TE, Jap TS, Hsiao LC, Lee SH, et al. (2008) Beneficial effects of insulin on glycemic control and beta-cell function in newly diagnosed type 2 diabetes with severe hyperglycemia after short-term intensive insulin therapy. Diabetes Care 31: 1927-1932.

35. Hu Y, Li L, Xu Y, Yu T, Tong G, et al. (2011) Shortterm intensive therapy in newly diagnosed type 2 diabetes partially restores both insulin sensitivity and $\beta$-cell function in subjects with long-term remission. Diabetes Care 34: 1848-1853.

36. Owens DR (2013) Clinical evidence for the earlier initiation of insulin therapy in type 2 diabetes. Diabetes Technol Ther 15: 776-785.

37. Bunck MC, Diamant M, Cornér A, Eliasson B, Malloy JL, et al. (2009) One-year treatment with exenatide improves beta-cell function, compared with insulin glargine, in metformin-treated type 2 diabetic patients: a randomized, controlled trial. Diabetes Care 32: $762-$ 768.

38. Bunck MC, Cornér A, Eliasson B, Heine RJ, Shaginian RM, et al. (2011) Effects of exenatide on measures of $\beta$-cell function after 3 years in metformin-treated patients with type 2 diabetes. Diabetes Care 34: 20412047.

39. Xu W, Bi Y, Sun Z, Li J, Guo L, et al. (2015) Comparison of the effects on glycaemic control and $\beta$-cell function in newly diagnosed type 2 diabetes patients of treatment with exenatide, insulin or pioglitazone: a multicentre randomized parallel-group trial (the CONFIDENCE study). J Intern Med 277: 137-150.

40. Shao Y, Yuan G, Feng Y, Zhang J, Guo X (2014) Early liraglutide treatment is better in glucose control, $\beta$-cell function improvement and mass preservation in $\mathrm{db} / \mathrm{db}$ mice. Peptides 52: 134-142.

41. D'Amour KA, Bang AG, Eliazer S, Kelly OG, Agulnick AD, et al. (2006) Production of pancreatic hormoneexpressing endocrine cells from human embryonic stem cells. Nat Biotechnol 24: 1392-1401.

42. Parnaud G, Bosco D, Berney T, Pattou F, Kerr-Conte J, et al. (2008) Proliferation of sorted human and rat beta cells. Diabetologia 51: 91-100.

43. Utzschneider KM, Carr DB, Barsness SM, Kahn SE, Schwartz RS (2004) Diet-induced weight loss is associated with an improvement in beta-cell function in older men. J Clin Endocrinol Metab 89: 2704-2710.

44. Solomon TP, Haus JM, Kelly KR, Rocco M, Kashyap SR, et al. (2010) Improved pancreatic beta-cell function in type 2 diabetic patients after lifestyle-induced weight loss is related to glucose-dependent insulinotropic polypeptide. Diabetes Care 33: 1561-1566.

45. Maeda H, Kubota A, Tanaka Y, Terauchi Y, Matsuba I, et al. (2012) The safety, efficacy and predictors for HbA1c reduction of sitagliptin in the treatment of Japanese type 2 diabetes. Diabetes Res Clin Pract 95: e20-e22.

46. Nauck MA, Vardarli I, Deacon CF, Holst JJ, Meier JJ (2011) Secretion of glucagon-like peptide-1 (GLP-1) in type 2 diabetes: what is up, what is down? Diabetologia 54: $10-18$.

47. Retnakaran R, Kramer CK, Choi H, Swaminathan B, Zinman B (2014) Liraglutide and the Preservation of Pancreatic $\beta$-Cell Function in Early Type 2 Diabetes: The LIBRA Trial. Diabetes Care 37: 3270-3278.

48. Ohta A, Kato H, Murayama K, Hashimoto E, Murakami $M$, et al. (2014) Effect of insulin glargine on endogenous insulin secretion and beta-cell function in Japanese type 2 diabetic patients using oral antidiabetic drugs. Endocr J 61: 13-18.

49. Pistrosch F, Köhler C, Schaper F, Landgraf W, Forst T, et al. (2013) Effects of insulin glargine versus metformin on glycemic variability, microvascular and betacell function in early type 2 diabetes. Acta Diabetol 50: 587-595.

50. Bi Y, Tong GY, Yang HJ, Cai MY, Ma JH, et al. (2013) The beneficial effect of metformin on $\beta$-cell function in non-obese Chinese subjects with newly diagnosed type 2 diabetes. Diabetes Metab Res Rev 29: 664-672. 